
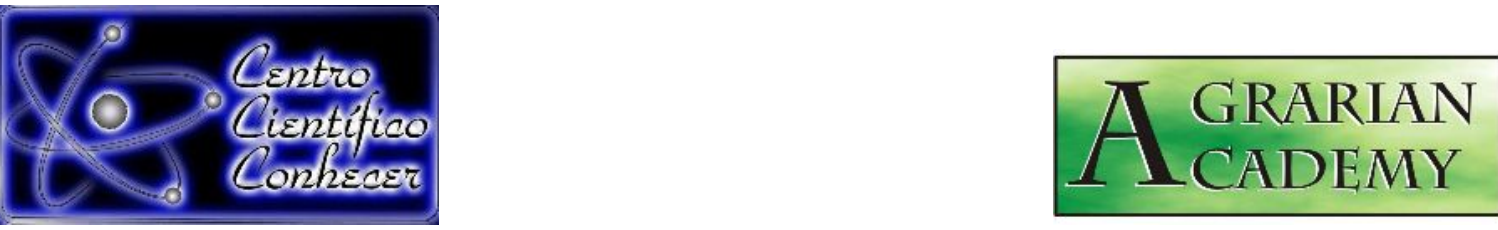

\title{
USO DE GEOTECNOLOGIAS NA DINÂMICA DE OCUPAÇÃO DOS SOLOS NO MUNICÍPIO DE PARANAITA-MT
}

Maxsueymer Silva ${ }^{1}$; Eder de Camargo Deluski ${ }^{2}$; Sylvia Karla Ferreira dos Santos ${ }^{2}$; Wesley Vicentino Claudino ${ }^{2}$, Edgley Pereira da Silva ${ }^{3}$

${ }^{1}$ Engenheiro Florestal (edyps2004@hotmail.com) Alta Floresta/MT, Brasil

${ }^{2}$ Professor da Faculdade de Ciências Agrárias e Biológicas, UNEMAT, Alta Floresta/MT, Brasil.

${ }^{3}$ Professor Doutor da Faculdade de Ciências Agrárias e Biológicas, UNEMAT, Alta Floresta/MT, Brasil.

Recebido em: 14/07/2018 - Aprovado em: 28/07/2018 - Publicado em: 31/07/2018

DOI: 10.18677/Agrarian_Academy_2018a33

\begin{abstract}
RESUMO
Este trabalho tem por objetivo produzir dados de desmatamento no município de Paranaíta-MT, nos anos de 1986, 1990, 2000, 2010 e 2016. Como subsídio para caracterização da dinâmica de uso e cobertura dos solos do município. Neste estudo utilizaram-se imagens dos satélites dos anos de interesse, para obtenção do uso e ocupação do solo, gerando mapas temáticos e Modelo Digital do Terreno (MDT), no município de Paranaíta-MT. A partir de então foi realizada uma análise quantitativa do uso do solo. O software específico para geoprocessamento (Arcgis 10.1, versão demonstrativa), bases cartográficas, entre outros. Para o ano de 1986 o território de Paranaíta apresentava $81,23 \%$ desse território constituído por vegetação natural. Comparando o ano de 1986 a 1990 houve uma supressão de $8,43 \%$ de perda da cobertura vegetal. O ano de 2000 apresentou uma vegetação natural com 60,59\% do território municipal, essa perda da vegetação foi ocasionada para exploração agropecuária. Foi evidenciado comparando o ano de 1986 a 2010 houve uma perda equivalente a $-42,57 \%$ da vegetação natural. No ano de 2016 houve um acréscimo nos espelhos D'agua para 1,91\% devido a construção da barragem e as áreas ocupadas pelas pastagens as áreas de regeneração natural e vegetação alta tiveram uma queda em sua ocupação, ocupando uma área de 34094,34 ha. Com a construção da usina o município perdeu área explorada com atividades agropecuárias e florestais de 4.152,04 hectares de área alagada.
\end{abstract}

PALAVRAS-CHAVE: Mapeamento, Sensoriamento remoto, uso do solo.

\section{USE OF GEOTECHNOLOGIES IN THE DYNAMICS OF SOIL OCCUPATION IN THE MUNICIPALITY OF PARANAITA-MT}

\section{ABSTRACT}

This work aims to produce deforestation data in the municipality of Paranaíta-MT, from 1986 to 2016. As a subsidy to characterize the dynamics of land use and land 
cover in the municipality. In this study, a bibliographical review was carried out, using images from the satellites of the year 1986, 1990, 2000, 2010 to 2016, to obtain land use and occupation, generating thematic maps and Digital Terrain Model (TDM) in the municipality of Paranaíta-MT. From then on a quantitative analysis of soil use was carried out. The specific software for geoprocessing (Arcgis 10.1, demo version), cartographic bases, among others. For the year 1986 the territory of Paranaíta presented $81.23 \%$ of this territory constituted by natural vegetation. Comparing the year 1986 to 1990 there was a suppression of $8.43 \%$ loss of vegetation cover. The year 2000 presented a natural vegetation with $60.59 \%$ of the municipal territory, this loss of vegetation was occasioned for agricultural exploitation. It was evidenced comparing the year 1986 to 2010 there was a loss equivalent to $-42.57 \%$ of the natural vegetation. In the year 2016 there was an increase in the water mirrors to $1.91 \%$ due to the construction of the dam and the areas occupied by the pastures the areas of natural regeneration and high vegetation had a fall in their occupation, occupying an area of 34094.34 there is. With the construction of the plant the municipality lost area exploited with agricultural and forestry activities of $4,152.04$ hectares of flooded area.

KEYWORDS: Mapping, Soil use, Remote Sensing

\section{INTRODUÇÃO}

A Amazônia possui a maior reserva de biodiversidade do planeta e é também a região que sofre uma grande pressão antrópica e de expansão da fronteira agrícola brasileira (SCHLINDWEIN, 2014), no estado do Mato Grosso não é diferente, vem passando por profundas mudanças decorrentes do processo de ocupação, desenvolvido na maioria das vezes com desmatamentos extensivos, exploração mineral e atividades agropecuárias, deixando na maioria do território fortes marcas destas intervenções antrópicas (COSTA, 2006).

A utilização da geotecnologia no monitoramento e identificação no uso e ocupação do solo é possível devido ao grande desenvolvimento de sofisticados algoritmos e a sua incorporação ao conjunto de funções dos Sistemas de Informações Geográficas (SIG), tem sido possível o processamento rápido e eficiente dos dados necessários para caracterização das variáveis morfométricas do solo, essenciais para análise das intervenções antrópicas em áreas desmatadas (OLIVEIRA, 2002). As aplicações dessa ferramenta são inúmeras, que podem ser trabalhadas, tanto nas paisagens urbanas, quanto no rural, podendo ser utilizada pelo poder público, em diferentes tomadas de decisões, mas principalmente no monitoramento do uso e ocupação da terra (BARROS, 2012).

A ação do homem no uso e ocupação territorial, em sua maioria das vezes ocorre de forma desordena e sem planejamento, isso acarreta significativas transformações, degradando de forma mais rápida os recursos naturais. Isso ocorre devido à grande potencialidade do uso madeireiro na região norte e o crescimento da pecuária e agricultura. $O$ uso de imagens de satélite é o melhor caminho para gerenciar e diagnosticar o comportamento e o potencial agrícola de uma região (CRISPIM; ALBANO, 2016). O desmatamento em geral está ligado à ocupação territorial desordenada, se constitui de operações que visam à retirada da vegetação nativa de uma determinada área para o uso alternativo do solo, ou seja, é qualquer descaracterização que venha a suprimir toda vegetação nativa de uma área (IBAMA, 2015). 
Este trabalho teve por objetivo produzir dados de desmatamento no município de Paranaíta-MT, nos anos de 1986, 1990, 2000, 2010 e 2016. Como subsídio para caracterização da dinâmica de uso e cobertura dos solos do município.

\section{MATERIAIS E MÉTODOS}

\section{Localização da área de estudo}

A área de estudo compreende ao município de Paranaíta-MT, com a localização na coordenadas geográfica central de 09 $39^{\prime}$ '53" latitude sul e $56^{\circ} 28^{\prime}$ 36 " longitude oeste. Ocupa uma área $6.445,05 \mathrm{~km}^{2}$ e distante aproximadamente 900 km da capital do estado Cuiabá-MT.

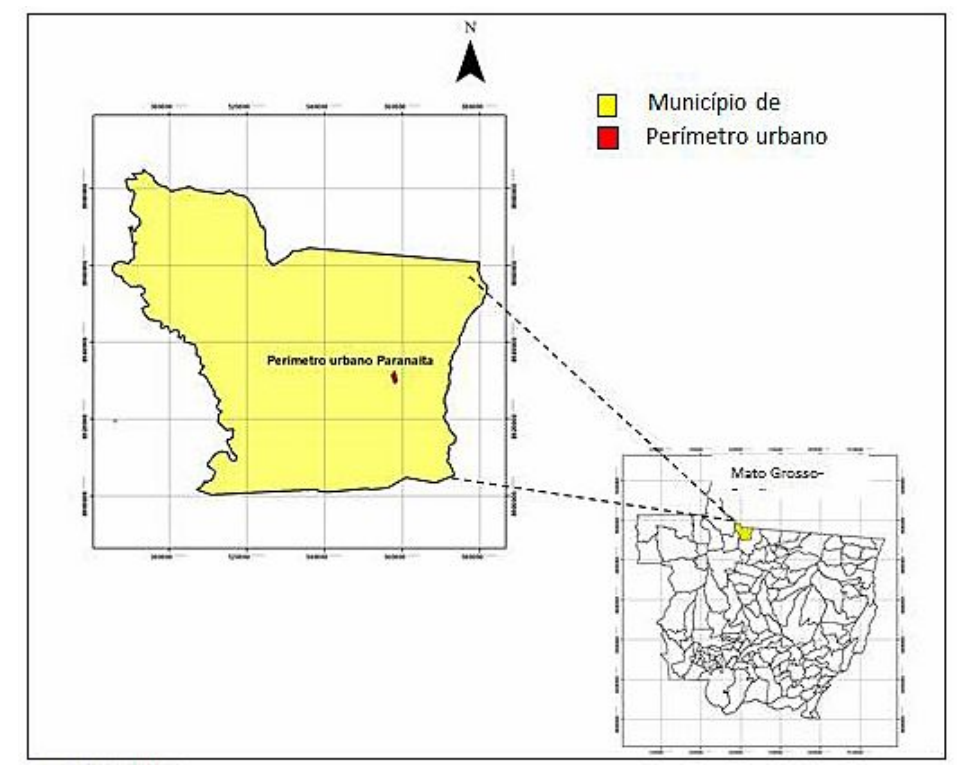

FIGURA 1 Mapa de localização do município de Paranaíta, MT. Fonte: Os autores

O clima predominante no município é o equatorial quente e úmido, com precipitações entre 250 e $1.000 \mathrm{~mm}$ as médias anuais, temperatura variando de 19,6 ${ }^{\circ} \mathrm{C}$ a $32,4 \stackrel{\circ}{\circ}$. O quadro florístico no município de Paranaíta, fundamentalmente, é constituído por Floresta Ombrófila Aberta e Densa, Floresta Estacional e Cerrado (IBGE, 2012). Os tipos de solos predominantes são solos Podzólicos (Amarelo e Vermelho-Amarelo), Latossolos e Hidromórficos (MIRANDA, 2016).

\section{Procedimentos metodológicos}

$\mathrm{Na}$ elaboração do trabalho foram utilizadas imagens do satélite Landsat 5 na composição RGB 7,4,2 e OLI-Landsat-8 com a composição RGB 6, 5, 4 com resolução espacial de 30 e 15 metros, disponibilizadas pelo site Earth Explorer nas datas de Agosto de 1986, 1990, 2000, 2010, 2010 e 2016. As imagens passaram por um processo de contraste que possibilitou a melhor visualização dos diferentes aspectos que a imagem possui. Para geração do mapa de Uso e Cobertura da Terra, foram levantadas informações temáticas obtidas a partir de interpretação visual. De modo a facilitar a classificação das classes.

$\mathrm{Na}$ determinação das classes de uso da terra foram realizadas classificações 
do tipo: supervisionada, sendo coletado no mínimo cinco amostras para cada classe. Foi quantificada a área de cada classe por meio da tabela de atributos, com o nome de "área" e a partir desse campo, calculou-se a área em hectares, sendo possível o conhecimento do tamanho de área de cada classe. A classificação supervisionada foi confeccionada através da seleção manual de amostras de treinamento, referentes a cada classe de uso, baseando-se em chaves de interpretação visual (Quadro 1).

Quadro 1. Chave para Identificação das classes de Uso e Cobertura da Terra.

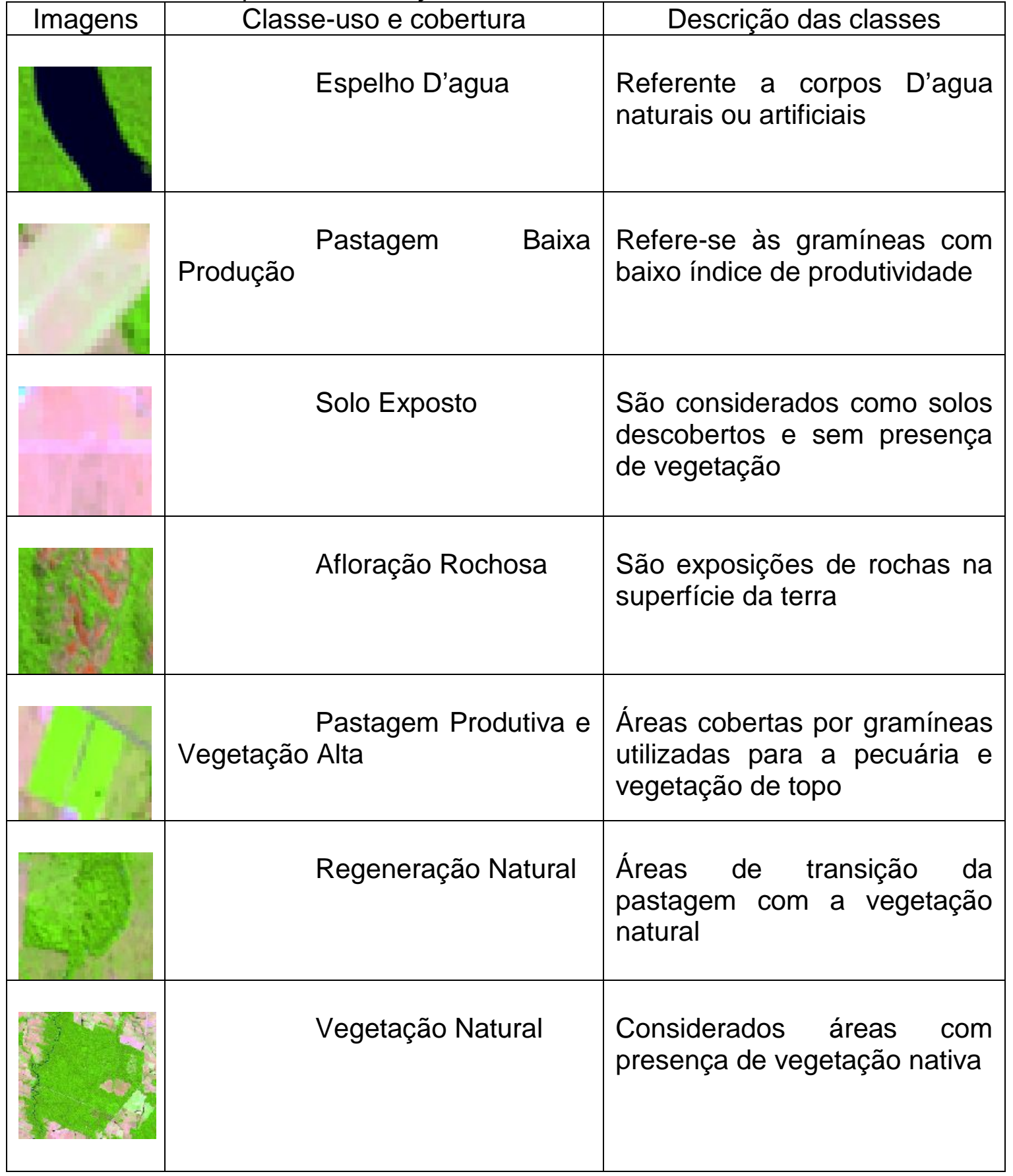

Fonte: autores. 
Após a extração dos dados obtidos através de imagens processadas no programa ArcGis. A confecção de mapas tem como finalidade a determinação das áreas de incompatibilidade entre o uso e cobertura da terra e as condicionantes legais propostas pelo Código Florestal regido pela Lei 4.771, de 15 de setembro de 1965.

Nos mapas foram determinadas as áreas em hectare do limite municipal, espelho D'agua, pastagem de baixa produção, solo exposto, afloramento rochoso, pastagem produtiva e vegetação alta, regeneração natural, vegetação natural. O mapa de uso e ocupação dos solos foi gerado a partir de processamento digital das imagens orbitais.

\section{RESULTADOS E DISCUSSÃO}

Em meados dos anos 80 no Brasil foi criada uma política conhecida como ocupar para não perder, onde, o governo incentivava a colonização do norte do país. Essa colonização veio de forma desordenada que contribuiu para os grandes índices de desflorestamento, transformando o que era vegetação natural em vegetação em pastagem, afim, de inserir a criação de gado e a venda da madeira (SANTOS, 2013).

As classificações das ocupações dos solos foram feitas no perímetro de 482.353,71 hectares (ha) que equivalem a todo o território de Paranaíta. Conforme a (Tabela 1) do ano de 1986, 81,23\% desse território eram constituídos por vegetação natural ocupando $391.797,09$ ha, as regenerações naturais e vegetação alta ocupam um total de hectare de $47.889,54 \mathrm{com} 9,93 \%$ de sua ocupação, espelhos D'agua com certa de 4819,59 ha que representa $1 \%$, já o afloramento rochoso tem uma área de 1261,53 ficando com apenas $0,26 \%$ do total. A regeneração natural depende de condições ambientais favoráveis, para promover a formação, dispersão, germinação e vigoramento das plantas (FRAGOSO et al. 2016).

Pode-se observar que os principais agentes causadores do desflorestamento são as transformações da vegetação natural em pastagem, sendo ela, pastagem produtiva com 5832,42 ha correspondendo a $1,21 \%$ e pastagem de baixa produção com 25445,88 ha com $5,28 \%$, uma boa parte dessas transformações resultou em solo exposto abrangendo uma área de 5307,66 ha, tendo $1,10 \%$ da área. Para melhor compreensão desses dados foi feito o mapa de ocupação de cada classe, segue (figura 2).

TABELA 1. Ocupação em hectare e porcentagem do ano de 1986. Município de Paranaíta, MT

\begin{tabular}{lrr}
\hline Ano 1986 & $\begin{array}{c}\text { Hectare } \\
\text { (ha) }\end{array}$ & $\begin{array}{c}\text { Porcentagem } \\
\text { (\%) }\end{array}$ \\
\hline Espelho D'agua & 4819,59 & 1,00 \\
Pastagem Baixa Produção & 25445,88 & 5,28 \\
Solo Exposto & 5307,66 & 1,10 \\
Afloramento Rochoso & 1261,53 & 0,26 \\
Pastagem Produtiva & 5832,42 & 1,21 \\
Regeneração Natural e Vegetação Alta & 47889,54 & 9,93 \\
Vegetação Natural & 391797,09 & 81,23 \\
Somatória & 482353,74 & 100,00 \\
\hline
\end{tabular}




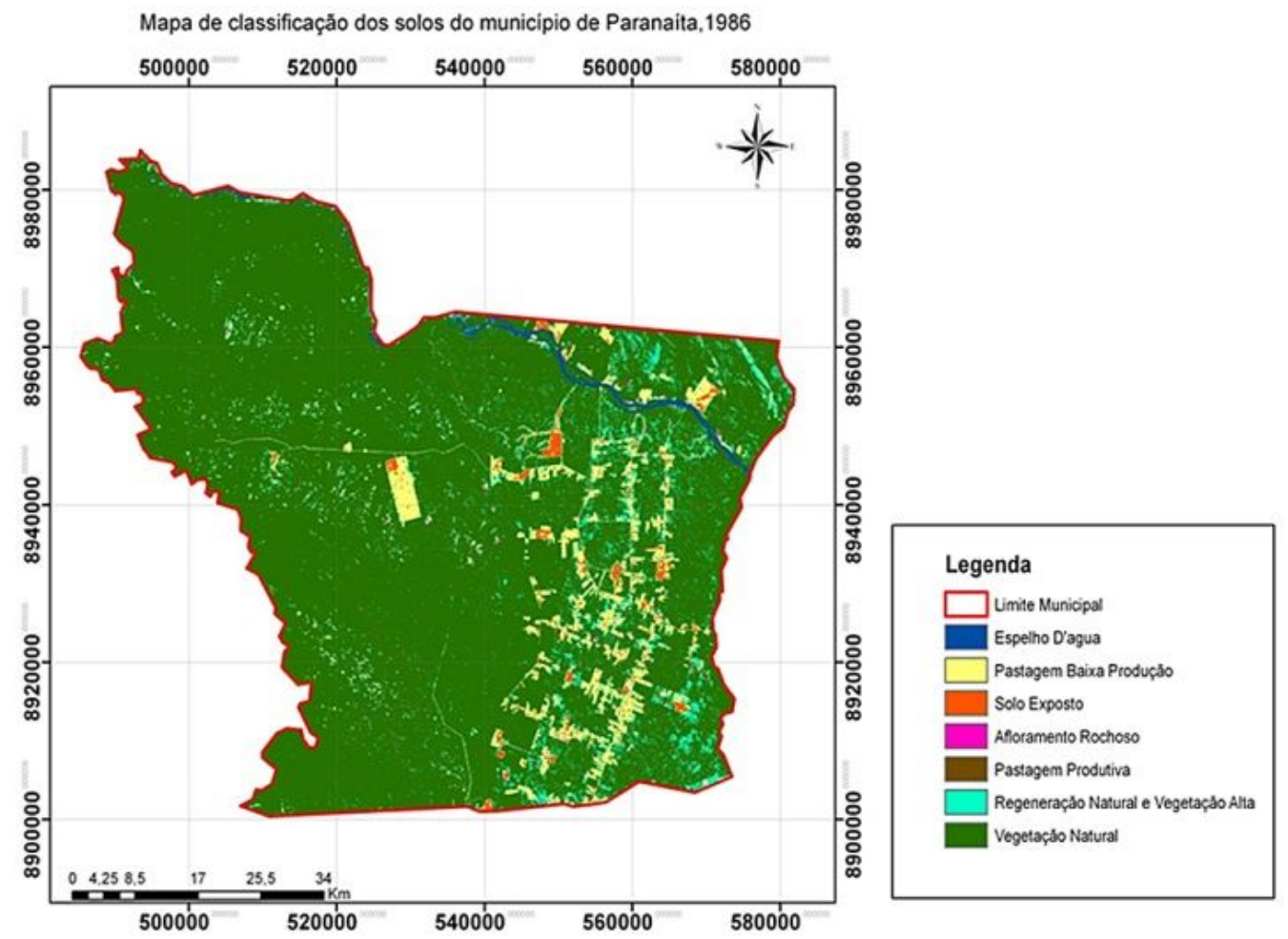

FIGURA 2. Mapa de classificação de solos, ano 1986. Município de Paranaíta-MT. Fonte: Os autores

De acordo a Tabela 2, a situação encontrada no ano de 1990 foi de que a vegetação natural ocupava uma área de 350.045,64 ha que equivalem a uma porcentagem de $72,57 \%$ da área de Paranaíta, já a regeneração natural e vegetação alta ocuparam uma área de $86.624,01$ ha com uma porcentagem de $17,96 \%$ da ocupação, quanto à pastagem produtiva teve uma queda para 4840,83 hectares comparada com o ano anterior de 1986, correspondendo a 1,00\% da área. Como pode ser observado na (Figura 3), com o devido o aumento do desmatamento as áreas de afloramento rochoso, 1432,26 ha e solo exposto com 12164,31 ha também aumentaram atingindo $0,30 \%$ e $2,52 \%$ da área, quanto a pastagem baixa produção teve uma diminuição de 4328,1 ha, ficando com 21117,78 há equivalente à $4,38 \% \mathrm{e}$ espelho D'agua aumentou sua porcentagem para 1,27\% num total de 6128,91 ha.

TABELA 2. Ocupação em hectare e porcentagem do ano de 1990.

\begin{tabular}{|c|c|c|}
\hline Ano 1990 & $\begin{array}{c}\text { Hectare } \\
\text { (ha) }\end{array}$ & $\begin{array}{c}\text { Porcentagem } \\
(\%)\end{array}$ \\
\hline Espelho D'agua & 6128,91 & 1,27 \\
\hline Pastagem Baixa Produção & 21117,78 & 4,38 \\
\hline Solo Exposto & 12164,31 & 2,52 \\
\hline Afloramento Rochoso & 1432,26 & 0,30 \\
\hline Pastagem Produtiva & 4840,83 & 1,00 \\
\hline Regeneração Natural e Vegetação Alta & 86624,01 & 17,96 \\
\hline Vegetação Natural & 350045,64 & 72,57 \\
\hline Somatória & 482353,74 & 100,00 \\
\hline
\end{tabular}




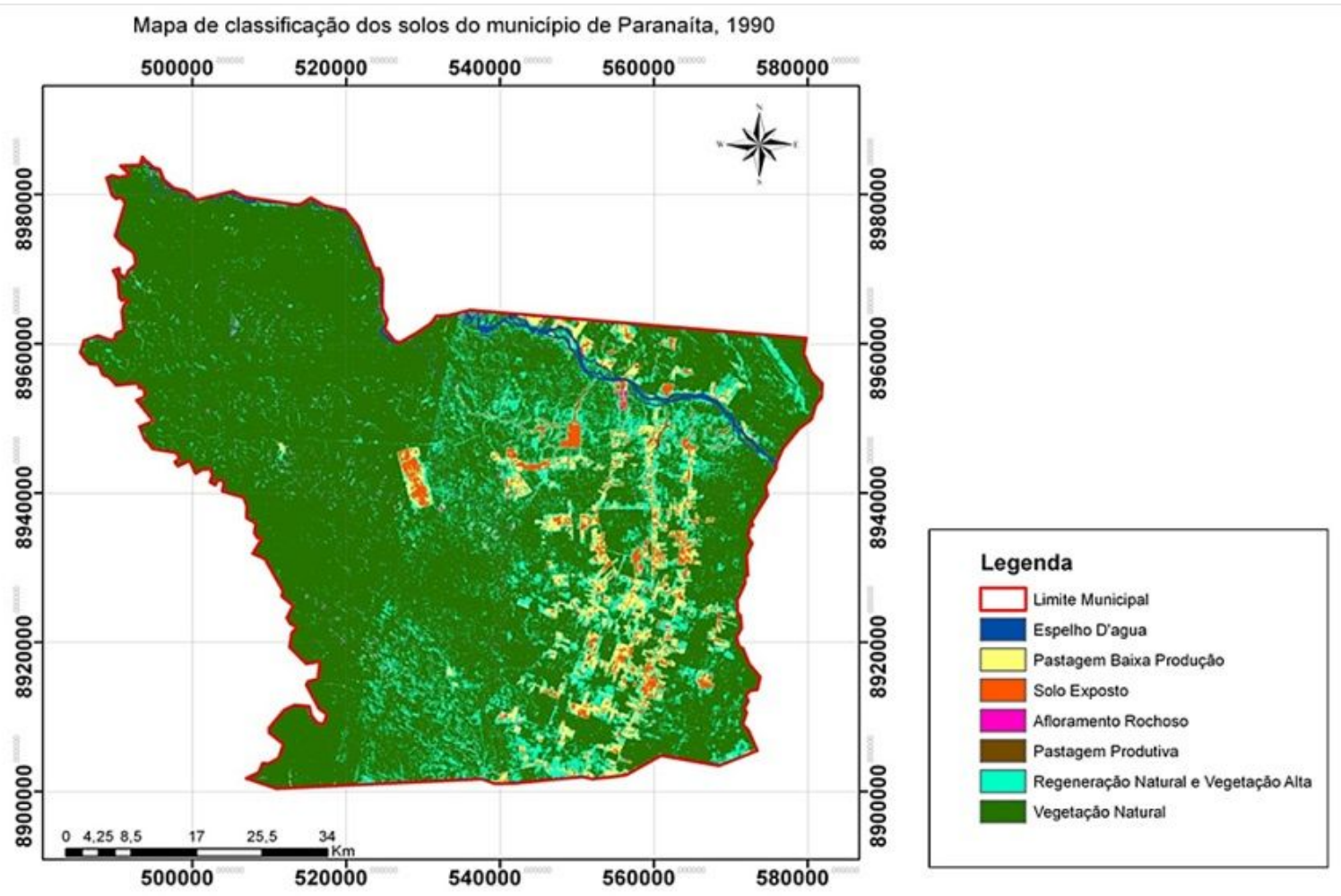

FIGURA 3. Mapa de classificação de solos, ano 1990. Município de Paranaíta, MT. Fonte: Os autores

No ano de 2000 houve uma diminuição na vegetação natural para 60,59\% e um aumento na pastagem produtiva para $4,07 \%$, dados estes mostrados na (Tabela 3) que representam um aumento positivo na pecuária do município de Paranaíta. $O$ avanço da fronteira agrícola no estado de Mato Grosso se apresenta em diferentes situações, desde a pecuária extrativista a grandes agroindústrias (SOUZA , 2016).

TABELA 3. Ocupação em hectare e porcentagem do ano de 2000.

\begin{tabular}{lrr}
\hline Ano 2000 & \multicolumn{1}{c}{$\begin{array}{c}\text { Hectare } \\
\text { (ha) }\end{array}$} & $\begin{array}{r}\text { Porcentagem } \\
\text { (\%) }\end{array}$ \\
\hline Espelho D'agua & 4584,69 & 0,95 \\
Pastagem Baixa Produção & 56139,21 & 11,64 \\
Solo Exposto & 14970,87 & 3,10 \\
Afloramento Rochoso & 1896,93 & 0,39 \\
Pastagem Produtiva & 19620,72 & 4,07 \\
Regeneração Natural e Vegetação Alta & 92866,86 & 19,25 \\
Vegetação Natural & 292274,5 & 60,59 \\
Somatória & 482353,7 & 100,00 \\
\hline
\end{tabular}

Pode-se observar na (Figura 4) com aumento da transformação da área de vegetação natural para pastagens, as áreas de solo exposto 14970,87 ha e afloramento 1896,93 ha aumentaram acompanhado o nível de desmatamento, os índices de regeneração natural e pastagem alta também tiveram um aumento para $19,25 \%$ da área. A pastagem de baixa produção houve um aumento de $7,26 \%$ quando comparado com o ano anterior avaliado e espelho D'agua ocupa uma área de 45804,69 ha.

AGRARIAN ACADEMY, Centro Científico Conhecer - Goiânia, v.5, n.9; p.340 2018 


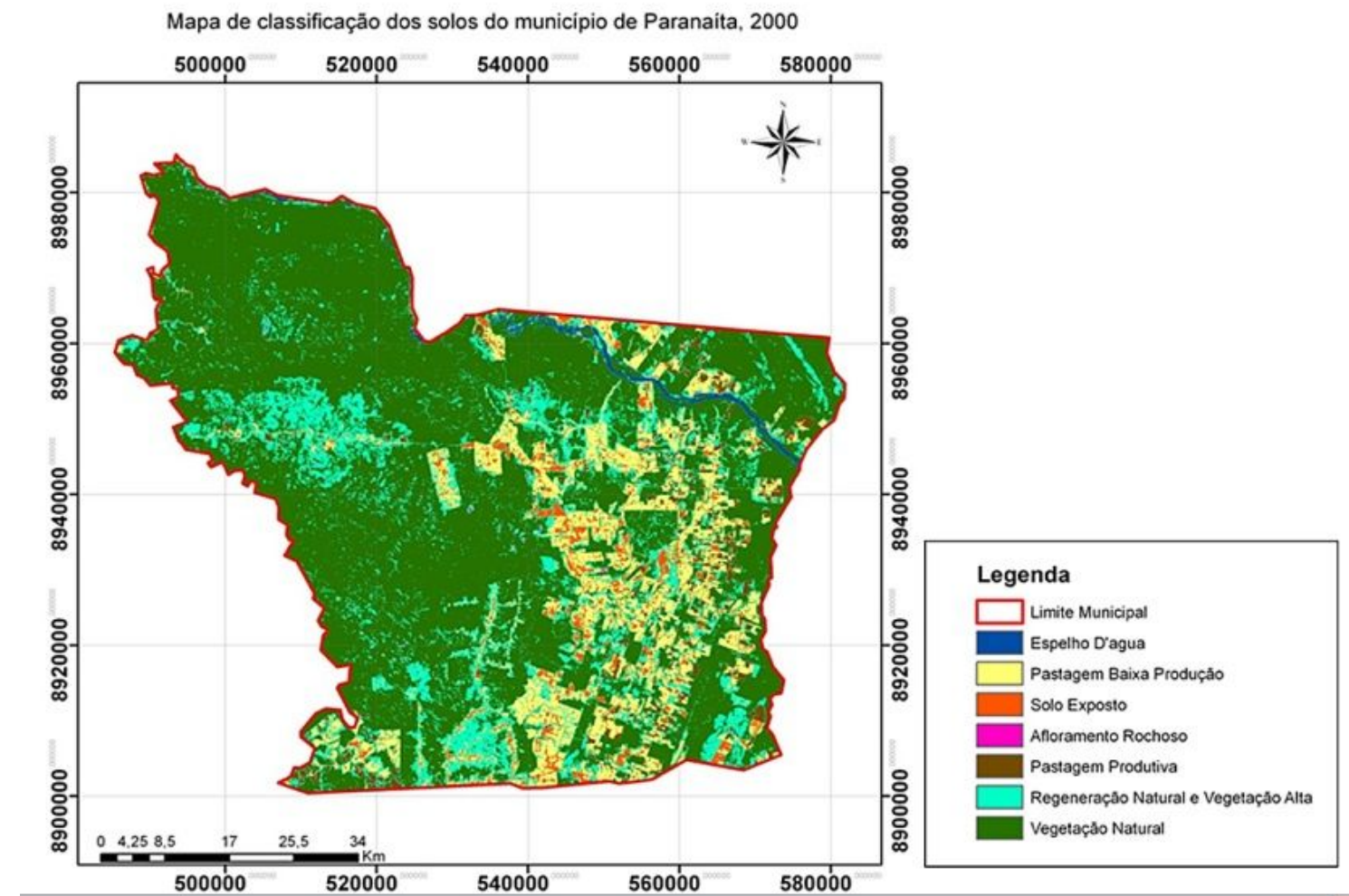

FIGURA 4. Mapa de classificação de solos, ano 2000. Município de

Paranaíta, MT. Fonte: Os autores

No ano de 2010, observado na Tabela 4, repara-se que a vegetação natural que está ocupando $38,33 \%$ da área tendo um aumento de desflorestamento comparado com os anos anteriores, o motivo desse desflorestamento deve-se ao crescimento da pecuária no município, onde as pastagens produtivas e pastagens de baixa produção ocupam $23,81 \%$ do território. As áreas de vegetação natural do ano de 2010 quando comparadas com a mesma área no ano de 1986 nota-se que houve um acréscimo de 49,90\% no índice de desmatamento.

TABELA 4. Ocupação em hectare e porcentagem do ano de 2010.

\begin{tabular}{lrr}
\hline Ano 2010 & \multicolumn{1}{c}{$\begin{array}{c}\text { Hectare } \\
\text { (ha) }\end{array}$} & $\begin{array}{r}\text { Porcentagem } \\
\text { (\%) }\end{array}$ \\
\hline Espelho D'água & 5121 & 1,06 \\
Pastagem Baixa Produção & 63795,6 & 13,23 \\
Solo Exposto & 41562,09 & 8,62 \\
Afloramento Rochoso & 2426,49 & 0,50 \\
Pastagem Produtiva & 51028,92 & 10,58 \\
Regeneração Natural e Vegetação Alta & 133555,59 & 27,69 \\
Vegetação Natural & 184864,05 & 38,33 \\
Somatória & 482353,74 & 100,00 \\
\hline
\end{tabular}

Devido ao desflorestamento nos anos de 2000 a 2010 verifica-se na figura 5 uma grande porção de solo exposto que ocupa área de 41562,09 ha, subsequentemente houve aumento no afloramento rochoso que passou a ocupar 
$0,50 \%$ da área, tais aumentos ocorreram através do aumento do desmatamento. $A$ regeneração natural e a vegetação alta teve aumento para $27,69 \%$ e espelho D'agua está ocupando uma área de 5121 ha. Já o solo exposto e afloramento rochoso quando comparado com o ano anterior avaliado teve um crescimento de $0,54 \%$.

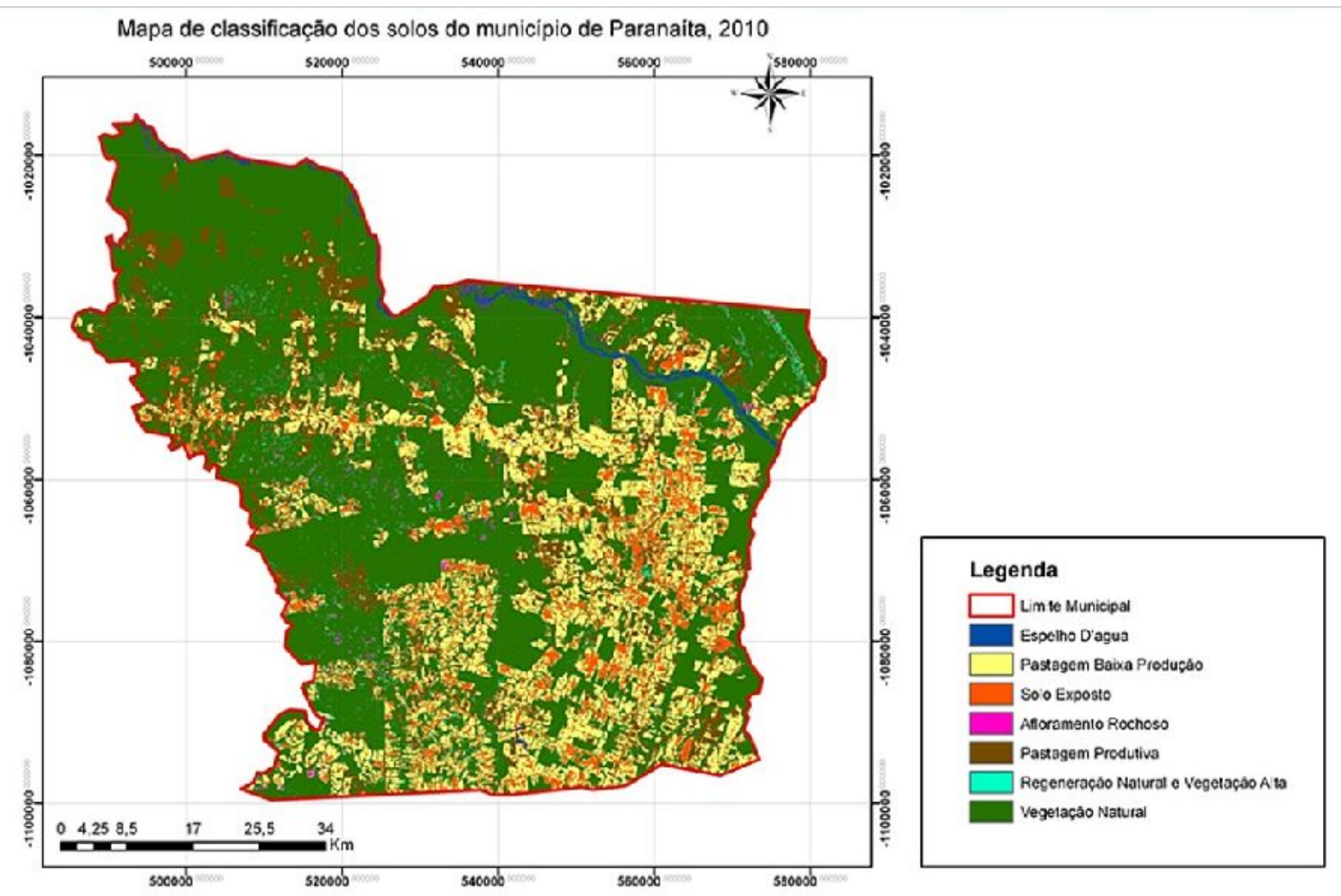

FIGURA 2. Mapa de classificação de solos, ano 2010. Município de Paranaíta, MT. Fonte: Os autores

Já para o ano de 2016, último ano avaliado, a Tabela 5 mostra que o desflorestamento para desenvolvimento da pecuária foi crescente em que as áreas ocupadas por pastagens, seja ela produtiva ou de baixa produção ocupam área de $157.893,3$ ha quando em proporção ocupam 32,73\% da área, sendo estas os principais percussores para a derrubada da vegetação natural que passou a ocupar $48,62 \%$ do território total, sendo esse território de 234.521,6 ha. Em detrimentos do aumento das pastagens, as áreas de regeneração natural e vegetação alta tiveram queda em sua ocupação, totalizando uma área de 34094,34 ha.

TABELA 5. Ocupação em hectare e porcentagem do ano de 2016.

\begin{tabular}{|c|c|c|}
\hline Ano 2016 & $\begin{array}{c}\text { Hectare } \\
\text { (ha) }\end{array}$ & $\begin{array}{c}\text { Porcentagem } \\
(\%)\end{array}$ \\
\hline Espelho D'agua & 9224,28 & 1,91 \\
\hline Pastagem Baixa Produção & 121714,2 & 25,23 \\
\hline Solo Exposto & 42806,79 & 8,87 \\
\hline Afloramento Rochoso & 3813,39 & 0,79 \\
\hline Pastagem Produtiva & 36179,1 & 7,50 \\
\hline Regeneração Natural e Vegetação Alta & 34094,34 & 7,07 \\
\hline Vegetação Natural & 234521,6 & 48,62 \\
\hline Somatória & 482353,7 & 100,00 \\
\hline
\end{tabular}

AGRARIAN ACADEMY, Centro Científico Conhecer - Goiânia, v.5, n.9; p.342 2018 
Observando a Figura 6 nota-se grande crescimento no espelho D'agua, isso ocorreu pela construção da barragem hidroelétrica no rio Teles Pires no município de Paranaíta, essa construção aumentou o espelho D'agua para 9224,28 ha, porcentagem que cresceu cerca de $0,91 \%$ comparada com o primeiro ano avaliado.

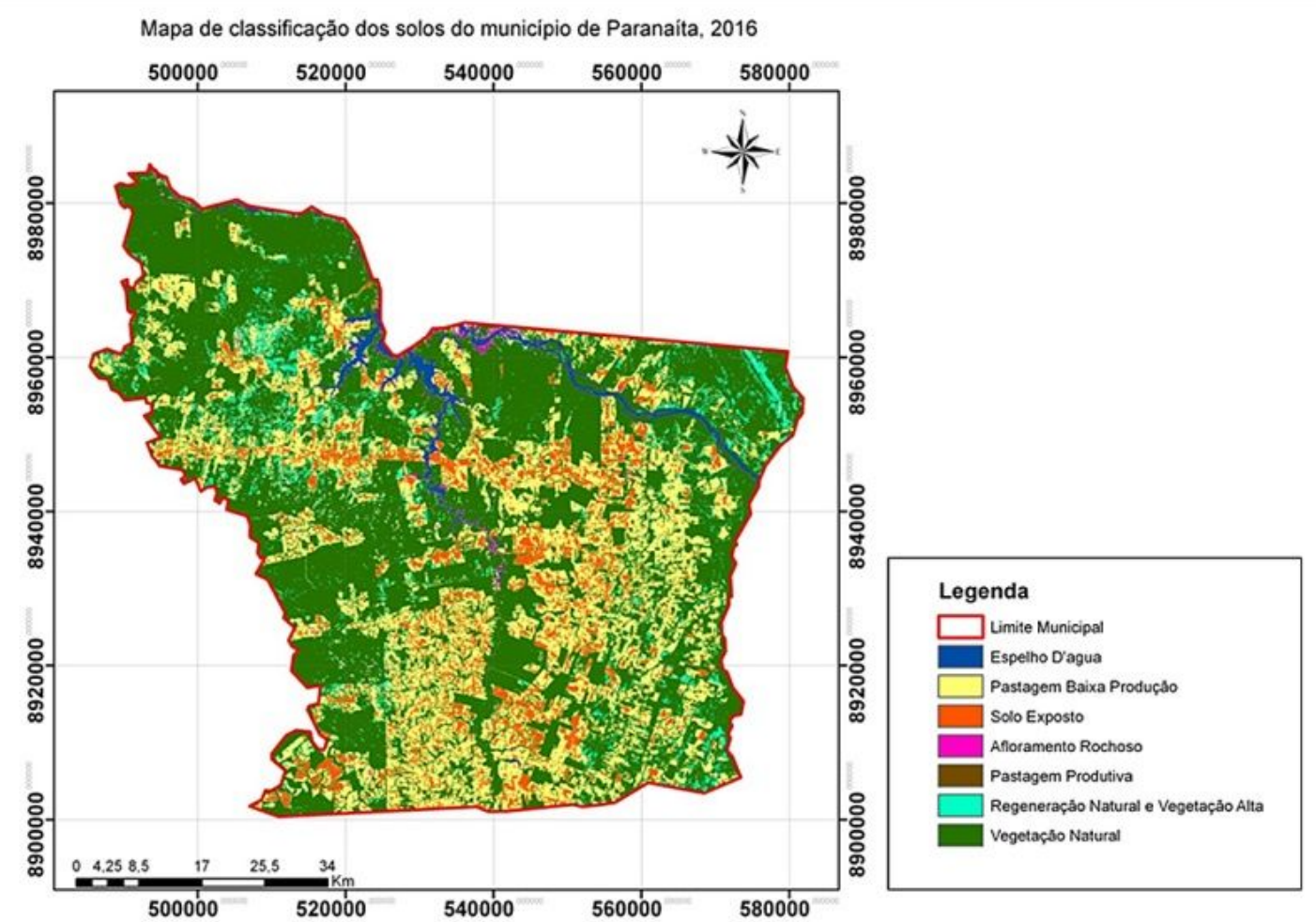

FIGURA 3. Mapa de classificação de solos ano 2016. Município de Paranaíta, MT. Fonte: Os autores

No ano de 2013 a Companhia Hidroelétrica Teles Pires iniciou o processo de construção da barragem hidroelétrica, neste mesmo ano houve o início da supressão da vegetação onde seria o alagamento devido a criação do reservatório terminando no ano de 2014. Após a construção da barragem e o término do enchimento do reservatório no ano de 2015 pode-se calcular a área de alagamento causada pela barragem, essa área impactada pela construção da usina chega 4.152,04 ha como mostra o mapa da área impactada pela construção da barragem (Figura 7). As hidrelétricas na região Amazônia trouxeram vários impactos negativos tais como o desmatamento e fragmentação são exemplos desses impactos.

As regiões em que as barragens são construídas atraem número considerável de imigrantes, que ocasionam o desmatamento na região da barragem, um exemplo esta na construção da usina de Belo Monte que atraiu quantidade considerável de pessoas na região de Altamira, Pará e sofreu um dos maiores pontos do desmatamento no ano de 2010 e 2011 (BARRETO at al., 2011). 


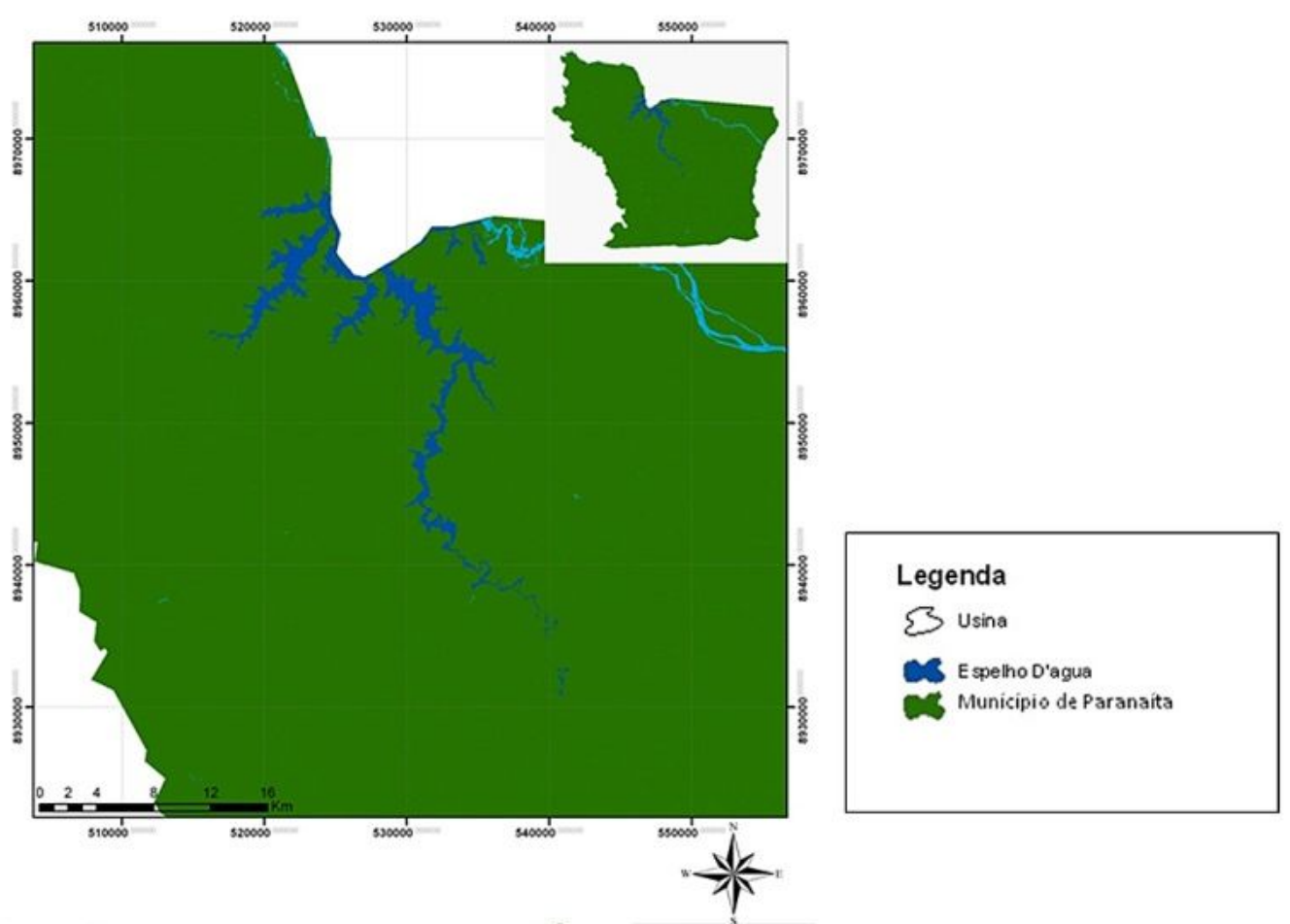

FIGURA 4. Mapa da área impactada pela barragem no município de Paranaíta-MT. Fonte: Os autores

Na Figura 8 observa-se o mapa da altimetria do município de Paranaíta, podem ser vistas a altura máxima que atinge 470 metros e mínima que chega a 141 metros dos relevos topográficos. Nas alturas de 251,667 m a $145,0 \mathrm{~m}$ ocorre a presença de malha hídrica, sendo estas vindo das partes mais altas para as mais baixas, já as áreas com alturas de $322,778 \mathrm{~m}$ a altitude de $465 \mathrm{~m}$ formam os divisores de água, enquanto o perímetro urbano de Paranaíta encontra-se entre as altitudes de $322,778 \mathrm{~m}$. a 287,222 m. de altura.

Relevo de Paranaita

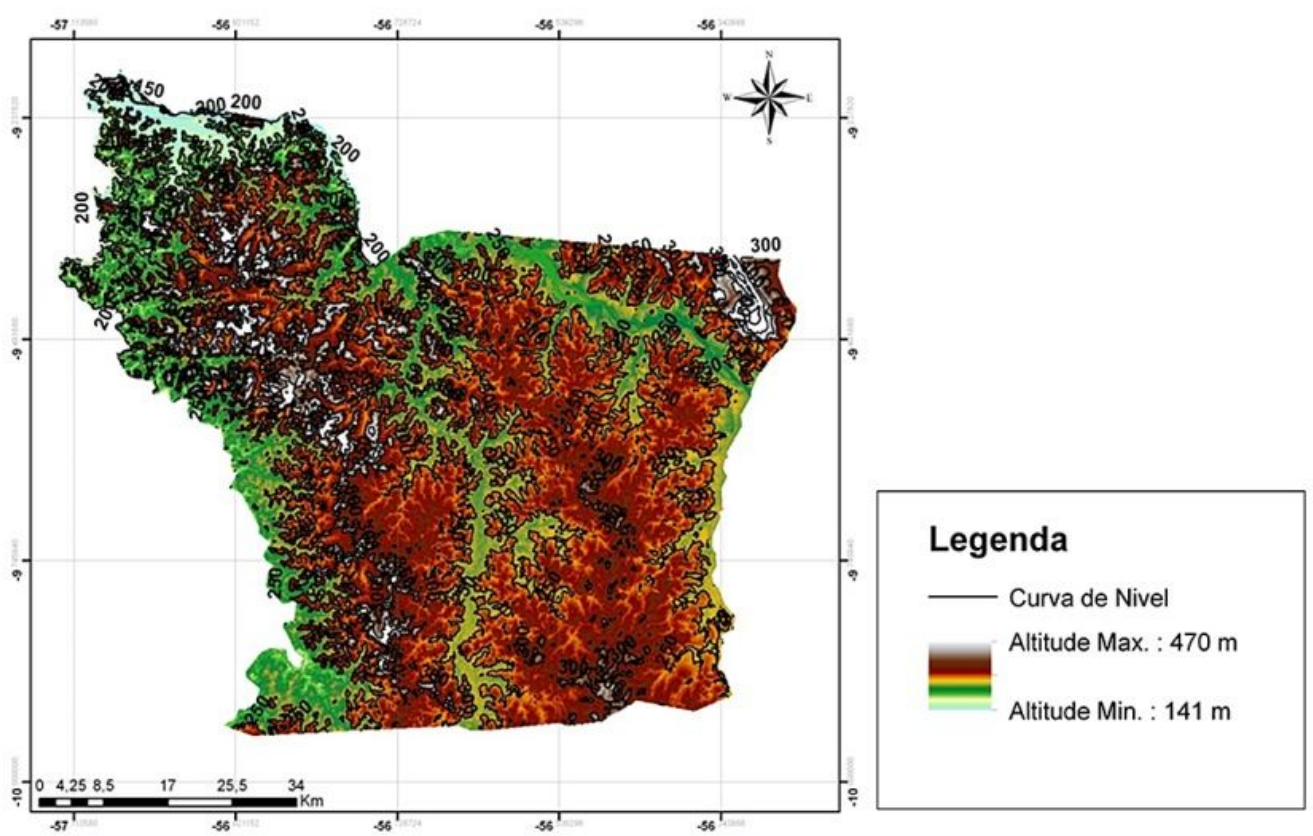

FIGURA 5. Mapa de altimetria do Município de Paranaíta-MT. Fonte: Os autores AGRARIAN ACADEMY, Centro Científico Conhecer - Goiânia, v.5, n.9; p. 3442018 


\section{CONCLUSÕES}

Para o ano de 1986 o território de Paranaíta apresentava $81,23 \%$ desse território constituído por vegetação natural.

Comparando o ano de 1986 a 1990 houve uma supressão de 8,43\% de perda da cobertura vegetal.

O ano de 2000 apresentou uma vegetação natural com $60,59 \%$ do território municipal, essa perda da vegetação foi ocasionada para exploração agropecuária.

Foi evidenciado comparando o ano de 1986 a 2010 houve uma perda equivalente a $-42,57 \%$ da vegetação natural.

Com a construção da usina o município perdeu área explorada com atividades agropecuárias e florestais de 4.152,04 hectares de área alagada.

\section{REFERÊNCIAS}

Barreto, P., A. Brandão Jr., H. Martins, D. Silva, C. Souza Jr., M. Sales \& T. Feitosa. 2011. Risco de Desmatamento Associado à Hidrelétrica de Belo Monte. Instituto do Homem e Meio Ambiente da Amazônia (IMAZON), Belém, PA. 98 p. Disponível em: http://www.imazon.org.br/publicacoes/livros/risco-de-desmatamentoassociado-a-hidreletrica-de-belo-monte/at_download/file

BARROS, C. G. D.; OLIVEIRA, G. A. Utilização de Imagens Landsat 5/TM e CBERS 2B/HRC na Discriminação do Uso e Ocupação do Solo no Município de VilhenaRondônia. Anais 4ํ Simpósio de Geotecnologias no Pantanal, Bonito, MS, 20-24 de outubro 2012. Embrapa Informática Agropecuária/INPE, p. 919-925.

COSTA, W. L. S. Análise espaço temporal do desmatamento e da efetividade do Sistema de Licenciamento de Propriedades Rurais do Estado de Mato grosso dentro do Bioma da Floresta Amazônica. Monografia (Especialização) - UFMG, 2006.

CRISPIM, L. C; ALBANO, A. O uso das imagens de satélite como recurso didático no ensino de geografia. Pesquisar - Revista de Estudos e Pesquisas em Ensino de Geografia, Florianópolis, v. 3, n. 4, p. 46-57. 2016.

FRAGOSO, R. O.; CARPANEZZI, A. A.; KOEHLER, H. S.; RIBAS, K. C. Barreiras ao Estabelecimento da Regeneração Natural em Áreas de Pastagens Abandonadas. Ciência Florestal, Santa Maria, v. 27, n. 4, p. 1451-1464, out.-dez., 2017. Disponível em: < http://www.redalyc.org/pdf/534/53453782030.pdf> Acesso em: 28 março de 2018.

IBGE. Instituto de Geografia e Estatística. Manual técnico da vegetação brasileira. $2^{2}$ Ed. Rio de Janeiro: Departamento de Recursos Naturais e Estudos Ambientais/IBGE, 2012. $271 \mathrm{p}$.

IBAMA - Instituto Brasileiro do Meio Ambiente e dos Recursos Naturais. Desmatamento - Áreas Temáticas, 2015. Online. Disponível em <http://www.ibama.gov.br/areastematicas/desmatamento> acesso em 19 de jan. de 2017.

MIRANDA, L. Atlas geográfico de Mato Grosso. 2ª Ed. Cuiabá: Entrelinhas, 2016. 64 AGRARIAN ACADEMY, Centro Científico Conhecer - Goiânia, v.5, n.9; p.345 2018 
p.

OLIVEIRA, M. J. Proposta Metodológica para Delimitação Automática de Áreas de Preservação Permanente em Topos de Morros e em Linha de Cumeada. 2002. 53p. Dissertação (Mestrado em Ciência Florestal) - Universidade Federal de Viçosa, UFV. Viçosa - MG.

SANTOS, J.C. A fronteira noroeste: entre colonos e garimpeiros de Juína - MT. In: XXVII Simpósio Nacional de História: conhecimento histórico e diálogo social; 2013, Natal. Anais... Natal, ANPUH Brasil, 2013.

SOUZA, R. Infraestruturas de Logística e Transporte em Mato Grosso: Uma leitura geográfica. 2016. 131p. Dissertação (Mestrado em Geografia). Programa de Pós-Graduação em Geografia, Universidade Federal de Mato Grosso. Rondonópolis, 2016

SCHLINDWEIN, J. A. Solos de Rondônia: Usos e perspectivas. In: Congresso sobre Recursos Naturais da Amazônia Ocidental: Sustentabilidade Ambiental, 19, 2012. Rolim de Moura-RO. Anais eletrônicos... Unir, 2014. Disponível em: Acesso em: 03 dez. 2014. 